\title{
Geração Y e a indústria de software do Brasil
}

\author{
Daniel Michelon De Carli ${ }^{1,2}$, Lisandra Manzoni Fontoura ${ }^{2}$, Liane Santiago \\ Cafarate $^{3}$, Graziele Camargo Kemmerich ${ }^{4}$
}

${ }^{1}$ Núcleo de Tecnologia da Informação e Comunicação (NTIC)

Universidade Federal do Pampa (UNIPAMPA)

Alegrete - RS - Brasil

${ }^{2}$ Programa de Pós-graduação em Informática (PPGI)

Mestrado em Computação - Universidade Federal de Santa Maria

Santa Maria - RS - Brasil

${ }^{3}$ Programa de Pós-graduação em Engenharia da Produção (PPGEP)

Mestrado em Engenharia da Produção - Universidade Federal de Santa Maria (UFSM)

Santa Maria - RS - Brasil

${ }^{4}$ Curso de Administração

Universidade Federal de Santa Maria (UFSM)

Santa Maria - RS - Brasil

\{daniel.de.carli, lisandramf,lianecafarate, grazikemmerich\}@gmail.com

\begin{abstract}
They are young, creative, focused on results and always looking for relationship and recognition. These people were born between 1980 and 1999 and they are known as generation $Y$. This generation represents the majority of workers in Information Technology (IT) segment in Brazil. Indeed, they fit important roles in management and operational teams in big corporations and startups that work with IT. This paper aims to map the profile of these young people, especially those related to the IT market, figuring out the historical background that helped this generation to assume theirs characteristics and showing ways to motivate and retain those professionals in the organizations.

Resumo. São jovens, criativos, focados em resultados e com busca constante de relacionamento e reconhecimento. As pessoas nascidas entre 1980 e 1999 são conhecidas como geração Y. No Brasil, representam a maioria dos profissionais da área da tecnologia da informação (TI). Assumem postos importantes de gestão e operacionais tanto em empresas consolidadas como em startups do segmento de TI. Esse trabalho busca, por meio de uma pesquisa quantitativa, mapear o perfil desses jovens, sobretudo, os que estão relacionados ao mercado de TI. Entender o cenário que propiciou o desenvolvimento dessa geração e suas características pode auxiliar na identificação de formas de motivar essa grande massa de trabalhadores a fim de retê-los nas organizações.
\end{abstract}

\section{Introdução}

Conforme o IBGE (2009), as três últimas décadas marcaram grandes mudanças mundiais, sobretudo em relação ao modelo econômico. Os modelos de produção vinculados a acumulação, até então vigentes, apresentaram mudanças significativas 
influenciadas pelo rápido desenvolvimento tecnológico, em especial destaca-se a influência das tecnologias da informação. A denominada "Sociedade da Informação" ganha espaço através de ferramentas computacionais de informação e comunicação. Os três pilares que sustentam essas mudanças, nessas últimas décadas, são: a microeletrônica, as telecomunicações e a informática.

Dentro desse contexto, pode-se visualizar o nascimento de uma nova geração, que tem foco em um ambiente de tecnologias e comunicação instantânea. Ela é formada por pessoas nascidas em meados da década de 80 até o final dos anos 90 e ficou conhecida como a geração Y. Diversas características são vinculadas a esses jovens, tais como: criatividade, foco em resultados e a busca constante de relacionamento e reconhecimento.

De forma específica, este artigo visa tratar de questões relevantes relacionadas à geração Y no mercado de trabalho na área de tecnologia da informação (TI). São objetivos desta pesquisa:

1. Identificar o ambiente que proporcionou o desenvolvimento da geração Y no Brasil;

2. Apresentar as principais características dessa geração nascida entre 1980 e 1999;

3. Verificar as proporções entre as diferentes gerações que atuam na área de desenvolvimento de software;

4. Constatar se os jogos eletrônicos influenciaram na formação de mão-de-obra na área de TI;

5. Verificar a alta rotatividade na área de desenvolvimento de software;

6. Avaliar pontos chaves na questão motivacional a fim de minimizar a alta rotatividade;

7. Apresentar possíveis estratégias, quanto ao ambiente de trabalho, com o objetivo de melhorar o desempenho desses jovens.

O presente trabalho está estruturado da seguinte forma: na seção 2 são apresentados alguns trabalhos relacionados; na seção 3 apresenta-se o contexto histórico e tecnológico no qual os jovens brasileiros da geração Y foram inseridos; na seção 4 busca-se caracterizar a geração $\mathrm{Y}$; na seção 5 são apresentadas algumas das principais vertentes em relação às teorias motivacionais; na seção 6 explana-se sobre o método aplicado e as limitações da pesquisa; na seção 7 são descritos os resultados alcançados, bem como sua interpretação; por fim, na seção 8, são apresentadas as considerações finais, estratégias para reter esses profissionais e trabalhos futuros.

\section{Trabalhos Relacionados}

Iannini (2010) desenvolve um trabalho que busca traçar o perfil dos profissionais da computação. O trabalho de Iannini apresenta objetivos relacionados a descobrir o nível de estudo dos profissionais, renda familiar, influência familiar na escolha da profissão, faixa etária, alguns fatores motivacionais entre outros dados. A sua pesquisa foi mais abrangente que esta em relação ao número de pessoas entrevistas, assumindo assim um perfil nacional. Por outro lado, não se preocupa em fazer uma análise e interpretação dos dados em relação ao perfil da geração Y. Além disso, alguns dados apresentados 
por Iannini contrariam o senso comum, por exemplo, ao afirmar que 40,2\% dos postos de trabalho na área de TI são ocupados por mulheres. Na pesquisa realizada nesse trabalho, essa taxa ficou em apenas $6,97 \%$.

Segundo a pesquisa realizada por Iannini (2010), 63\% dos profissionais estão na faixa dos 21 aos 29 anos de idade. Isso significa que pelo menos $63 \%$ dos profissionais são da geração Y o que, quando comparado com a pesquisa quantitativa desse trabalho é de $83,53 \%$. A diferença nos números pode ser vinculada as diferenças regionais visto que este trabalho apresentou um foco maior na região sul do Brasil. Contudo, ainda assim é evidenciado nas duas pesquisas que a geração $\mathrm{Y}$ ocupa a faixa de maior expressividade no setor.

Iannini (2010) no final de seu trabalho expressa a seguinte opinião sobre a geração Y: "É importante também as empresas se adequarem ao perfil comportamental desta geração, entendendo as atitudes predominantes da geração conhecida como Y, que precisa aprender a lidar com o fracasso, a planejar, tem mais facilidade em se impor, ... , tratam seus superiores como colegas, fazem o que gostam e dá prazer, além de serem indivíduos multitarefa". Contudo, Iannini não aborda o tema da geração Y com profundidade, apenas o menciona superficialmente no final de seu trabalho.

\section{Contexto Histórico}

O setor de tecnologia da informação emerge no Brasil a partir da década de 90 . Contudo, somente a partir de 2003, o governo brasileiro passa a perceber a importância do setor como instrumento de desenvolvimento econômico, social e cultural [IBGE 2009].

Vieira (2003) apresenta dados históricos que são diretamente relacionados à história da Internet no Brasil. Tais dados são de grande relevância, pois servem de subsídio para entender em que ambiente tecnológico os jovens brasileiros, nascidos durante as décadas de 80 e 90, ou seja, a geração Y [Oliveira 2010] foi estimulada.

Alguns dos primeiros casos da indústria de software nacional são apresentados por Vieira (2003). Em ordem cronológica, visualizam-se algumas datas que marcaram a história da tecnologia da informação e comunicação no Brasil e no mundo na Tabela 1.

É importante destacar outros acontecimentos de grande relevância para a Internet brasileira e mundial, que é o surgimento das redes de relacionamentos online, tais como Facebook e Orkut, fundados em 2004. O site Orkut é o segundo mais acessado no Brasil [Veja 2009]. Já o Facebook é a maior rede social do mundo conforme dados apresentados pela revista Veja (2009).

Com relação à microeletrônica, a sua evolução permitiu o desenvolvimento de jogos eletrônicos para computadores e videogames. $\mathrm{O}$ avanço nos processadores e redes de interconexão permitiu a criação da Internet como se conhece hoje. Esse cenário serve de base para identificar as grandes influências a que os jovens que fazem parte da geração Y foram, e ainda são, estimulados durante a sua juventude [Oliveira 2010]. 
Tabela 1: Principais acontecimentos que impactaram na Internet brasileira.

1988 Primeiro contato do Brasil com a Internet se dá quando a Fundação de Amparo à Pesquisa do estado de São Paulo (Fapesp) se conecta ao Fermilab, importante centro de pesquisa científica dos Estados Unidos.

1992 Fim da reserva de mercado no setor da informática no Brasil.

1995 Marco-zero da Internet comercial no mundo e no Brasil;

Surgem os primeiros sites de busca (Yahoo) e de comércio eletrônico (Amazon) nos Estados Unidos;

Surge o "Cadê?"- Empresa focada no mercado nacional de busca de web sites.

1996 Lançamento oficial da Booknet, um dos primeiros sites de e-commerce do Brasil, que posteriormente trocaria de nome para submarino.com.br;

O provedor de acesso e portal Universo Online foi ao ar.

1997 O provedor de acesso a Internet NutecNet se torna o ZAZ.

1998 Nasce o ZipMail no Brasil, empresa que oferece e-mail gratuito. A expectativa inicial era de conquistar 300 mil usuários ao final de um ano. Contudo, ao término dos 12 meses, o ZipMail já continha uma base de usuários superior a 1 milhão de cadastros.

1999 ZAZ vira o portal terra.com.br.

1999 Entrada de empresas estrangeiras em massa no mercado nacional; Nasce o iG, provedor de acesso grátis.

2000 Globo.com entra no mercado da mídia digital na Internet.

\section{Geração $Y$}

O conceito de geração reconhecido e aceito pela sociedade moderna estabelece um marco de vinte anos de separação entre as gerações. Isso ocorre porque aos 20 anos de idade, os jovens fazem as suas primeiras escolhas conjugais, políticas e profissionais. Isso significa que, a partir desse período, o jovem age e interfere significativamente na sociedade. Com o aumento da expectativa de vida, a redução da natalidade e a ampliação dos meios de comunicação, cria-se um momento único na história da humanidade, pois nunca cinco gerações diferentes conviveram em uma mesma realidade [Oliveira 2010].

As gerações são norteadas por valores diferentes principalmente dirigidos pelo contexto histórico em que foram criados. A reconstrução da sociedade do pós-segunda guerra mundial, vivida pela geração Belle Époque (nascida entre 1920 e 1939), apresentou grandes desafios. Valores como a importância da família e que as "coisas só são possíveis com muito sacrifício" foram marcantes para essas pessoas. Os Baby Boomers (1940-1959), por sua vez, são frutos da alta taxa de natalidade da geração anterior. Foram educados sobre uma cultura rígida na qual qualquer comportamento fora dos conceitos de obediência, disciplina e ordem eram considerados nocivos a sociedade. 
O período 1960 a 1979 foi marcado por grande conturbação social devido ao assassinato de grandes líderes políticos como Malcom X, que por sua vez, cedeu o X de seu nome para os nascidos nessa época, surge à geração X. Períodos de revoluções e aparecimento de movimentos sociais, como os hippies, fizeram parte constante do cenário mundial. Soma-se a isso, o uso da TV de forma significativa. Esse foi o contexto histórico a que a geração $\mathrm{X}$ fora estimulada durante a sua infância e juventude.

Já a geração Y, formada entre os nascidos entre 1980 a 1999, possui as seguintes características [Oliveira 2010]:

1. Curiosos e questionadores;

2. Extremamente informados;

3. Grande conhecimento de línguas, sobretudo o inglês;

4. Criativos;

5. A busca por novas experiências;

6. A opção por padrões informais;

7. Necessidade constante de reconhecimento;

8. Individualidade;

9. Relacionamentos e a busca por conexões. Esse fato, de certa forma, é um paradoxo se comparado com a característica da individualidade. Contudo, os jovens dessa geração têm a necessidade de compartilhar parte de suas vidas através do uso de redes de relacionamentos online;

10. Comunicação incessante. Através de programas de mensagem instantânea ( $m s n$, gtalk, etc), torpedos SMS, telefone celular e redes sociais online (Facebook, Orkut, Twitter, etc);

11. Projetos pessoais de prazos curtos e imediatos;

12. Foco em resultados. É importante salientar que esse aspecto apresenta prós e contras. A parte positiva é que o mercado e as atividades profissionais são construídas a partir de resultados. O ponto negativo é que esses jovens nem sempre estão preocupados em atingir os resultados esperados pela sua instituição;

13. Alta rotatividade em empregos.

\section{Teorias Motivacionais}

$\mathrm{Na}$ busca de formas para reter talentos, considera-se a motivação um dos pontos-chaves para estratégias bem sucedidas. Para isso é importante entender a base das teorias motivacionais, fazendo-se, assim, uma relação dos dados obtidos nessa pesquisa, sobre a geração Y, com a pirâmide motivacional de Abraham Maslow [Chiavenato 2000].

As diferentes gerações foram norteadas por diferentes valores e criadas em contextos históricos peculiares. As características de cada geração influenciam suas percepções e suas motivações. Nesse contexto é importante definirmos o que é motivação. Para Weisinger (1997), a motivação é aquilo que leva o indivíduo a despender energia numa direção específica com um propósito específico. Em termos organizacionais, motivação é sinônimo de alta produtividade, comprometimento com os objetivos e realização das metas da empresa [Ferreira, Fortuna, Tachizawa 2006].

Em relação à motivação, várias correntes e teorias foram desenvolvidas com o intuito de aprofundar o tema e aplicá-lo nas relações humanas, sobretudo, na questão do indivíduo. Sobre a teoria de Abraham Maslow e denominada de "Teoria da Hierarquia 
das Necessidades" - uma das mais conhecidas teorias sobre motivação que foi desenvolvida - as necessidades humanas dividem-se em cinco grupos, dispostos em uma ordem hierárquica. Quanto mais forte é a necessidade, mais intensa é a motivação. Uma vez satisfeita determinada necessidade, busca-se a satisfação da próxima ascendente [Maximiano 2007]. A pirâmide proposta por Maslow pode ser visualizada na Figura 1.

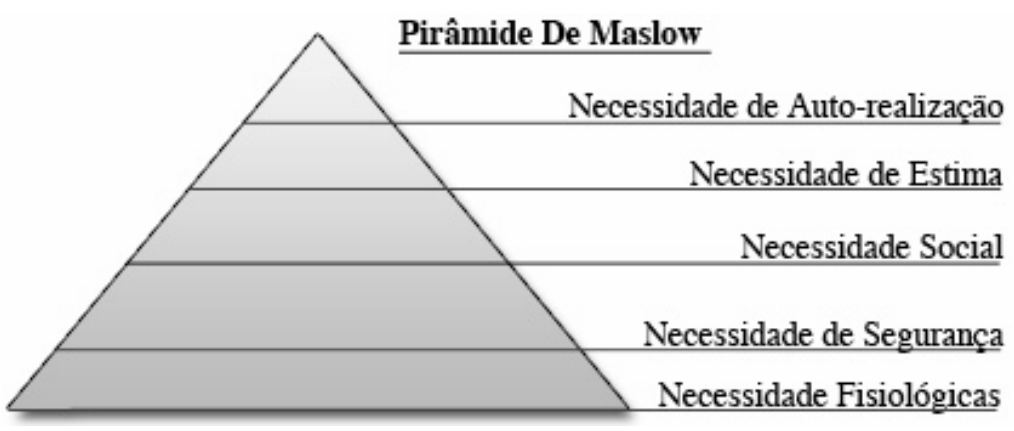

Figura 1. Pirâmide de Maslow

\section{Método Aplicado}

Para a realização deste trabalho, tomou-se como base uma revisão bibliográfica aprofundada sobre o tema geração Y. Questões como o cenário atual e a construção histórica das características do mercado de TI no Brasil são de grande importância para o entendimento de sua influência na construção dos profissionais nascidos entre 1980 e 1999.

Com o objetivo de mensurar dados estatísticos realizou-se uma pesquisa quantitativa por meio da aplicação de um questionário online para diversos profissionais da área. As hipóteses comportamentais e as características levadas em consideração para o desenvolvimento desse trabalho são baseadas nas teorias apresentas por Oliveira (2010) no seu livro “Geração Y - O Nascimento de uma Nova Versão de Líderes”. É importante destacar que as questões foram formuladas de forma subjetiva. Contudo, essa definição foi baseada nas características, hipóteses e teorias apresentadas por Oliveira (2010). Dessa forma, procura-se informações sobre a alta rotatividade das empresas, a influência dos jogos eletrônicos bem como as diversas características que colaboraram para a criação da geração Y.

Foram preenchidos 85 formulários através de uma ferramenta online, sobretudo na região sul do país. Optou-se pelo uso de ferramentas computacionais para a realização desse formulário em especial pelas características apresentadas por Oliveira (2010) sobre essa geração. Para o autor, a geração Y é composta de pessoas altamente conectadas e que utilizam redes de relacionamentos online. A estratégia de divulgação do formulário para o preenchimento se baseia na teoria que Oliveira (2010) apresenta a conectividade e o relacionamento online das pessoas como fator marcante no perfil desses jovens. Usou-se ferramentas como e-mail direcionados a profissionais $\mathrm{e}$ softwares de mensagens instantâneas para divulgar a pesquisa entre as pessoas da área. Essas pessoas, por sua vez, foram responsáveis por disseminar da pesquisa entre seus colegas de trabalho. O formulário esteve disponível online no período compreendido entre 9 a 12 de julho de 2010 e serviu de base para o desenvolvimento dessa pesquisa. 


\subsection{Limitações}

A principal limitação desse trabalho é a abrangência da amostra, predominantemente na região sul. Essa região foi escolhida devido a facilidade de disseminar os questionários nessa região, através da rede de contatos dos autores. Como trabalho futuro considera-se aplicar a pesquisa a nível nacional, bem como aumentar a quantidade de respondentes da pesquisa.

\section{Resultados da Pesquisa}

Nessa seção são apresentados os resultados obtidos na pesquisa. Na seção 7.1 apresentase o perfil geral dos respondentes, enquanto que, na seção 7.2, apresenta-se o perfil dos representantes da geração Y participantes da pesquisa.

\subsection{Resultados perfil geral}

A pesquisa apresenta que no Brasil, em especial na região sul, o sexo dos profissionais da área de desenvolvimento de software é majoritariamente do gênero masculino $(89,41 \%)$. A proporção de profissionais entre as diferentes gerações é outro fator importante a se destacar. Os representantes da geração Belle Époque, nascida entre 1920 e 1939, não aparecem nos resultados da pesquisa, provavelmente por serem pessoas já consideradas idosas e que possivelmente não tiveram contato com a computação em um estado mais maturo e amplamente difundido. Dessa forma, observa-se a ausência de representantes dessa geração nas profissões relacionadas ao desenvolvimento de softwares hoje.

A geração Baby Boomers apresentou poucos representantes que caracterizam a marca de $1,18 \%$. A geração $X$, por usa vez, é a segunda mais influente na área de desenvolvimento de software, apresenta uma proporção maior se comparado com as outras gerações anteriores, 15,29\%. Contudo, a grande fatia de mão-de-obra é formada por profissionais da geração Y. Ou seja, 83,53\% das pessoas entrevistadas.

\subsection{Resultados Geração Y}

Oliveira (2010) afirma que a geração iniciada na década de 80 foi fortemente influenciada pelo uso intenso do videogame. De fato, 93,06\%dos entrevistados da geração Y tinham como costume a atividade de jogar videogame. A fim de entender os aspectos motivacionais que levaram essas pessoas a atividades relacionadas ao entretenimento eletrônico, e procurar vincular um comparativo com as características atribuídas a geração $\mathrm{Y}$, foi elaborada a seguinte questão: "O que você considera mais importante nos jogos de videogame/computador?". A fim de avaliar o perfil dos entrevistados, foi atribuída a cada característica uma interpretação (ver Tabela 2).

A busca de novas experiências, representada na resposta "novas aventuras a cada fase", representa 48,61\%. Ou seja, foi o fator de maior relevância para o jovem em relação aos jogos de videogame em computador. A segunda resposta que mais apareceu na pesquisa foi "Desbravar todas as possibilidade que o jogo me permite", com 36,11\%, a qual se considera uma das possíveis representações para a característica "curiosidade". Já a competitividade e auto-superação apresentaram taxas bem menos expressivas. 
Tabela 2. O que você considera mais importante nos jogos de videogame/computador?

\begin{tabular}{|c|c|c|}
\hline Alternativas & Resposta & Interpretação \\
\hline Novas aventuras a cada fase & $48,61 \%$ & $\begin{array}{l}\text { Busca de novas } \\
\text { experiências }\end{array}$ \\
\hline $\begin{array}{l}\text { "Conquistar a maior pontuação possível" ou } \\
\text { "Comparar a minha pontuação com o meu melhor } \\
\text { desempenho anterior" }\end{array}$ & $8,34 \%$ & Auto-superação \\
\hline Comparar a minha pontuação com a dos meus amigos & $6,94 \%$ & Competitividade \\
\hline $\begin{array}{l}\text { Desbravar todas as possibilidades que o jogo me } \\
\text { permite }\end{array}$ & $36,11 \%$ & Curiosidade \\
\hline
\end{tabular}

Outra característica bastante relacionada aos jovens da geração $\mathrm{Y}$ é a alta rotatividade no emprego. Isso significa que esses profissionais facilmente trocam de emprego, como pode ser visualizado no gráfico exibido na Figura 2. Em torno de 55,5\% das pessoas da amostra já trocaram de emprego pelo menos três vezes, o que é uma taxa relativamente alta, pois a idade dessa geração, quando a pesquisa foi realizada, chega ao máximo em 30 anos.

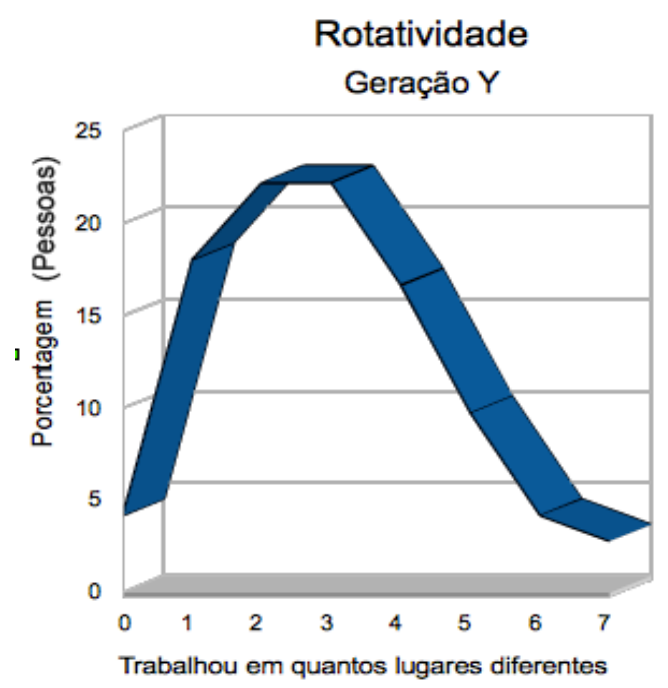

Figura 2. Gráfico da taxa de rotatividade

A fim de entender melhor os motivos que levam os profissionais a trocarem tanto de trabalho realizou-se a seguinte pergunta "Qual é o principal fator que lhe leva a troca de emprego". O principal fator que leva uma pessoa, na área de TI, a trocar de emprego é o salário, segundo os dados dessa pesquisa. Conforme Oliveira (2010), uma hipótese seria o perfil imediatista dessa geração, que não tem paciência para esperar o crescimento dentro da empresa e sempre estão em busca de novas oportunidades.

$\mathrm{Na}$ Tabela 3 pode-se visualizar os dados e a respectiva interpretação das respostas de acordo com a hierarquia proposta na pirâmide de Maslow [Maximiano 2007]. O desenvolvimento de atividades desafiadoras aparece no segundo ponto mais 
importante para a troca de emprego, com $15,28 \%$ das opiniões. Contudo a característica mais votada é a que pode apresentar a interpretação mais interessante. Ou seja, a resposta indica que, quando o salário é compatível com a atividade profissional, o ponto de maior relevância é a necessidade de reconhecimento e status. Caso contrário, o profissional buscará oportunidades condizentes com o que considera justos em relação à pretensão salarial.

Tabela 3. Qual é o principal fator que lhe leva a troca de emprego

\begin{tabular}{|c|c|c|}
\hline Alternativas & Respostas & $\begin{array}{l}\text { Interpretação: Pirâmide de } \\
\text { Maslow }\end{array}$ \\
\hline Melhor salário & $55,56 \%$ & Necessidade fisiológica (Base) \\
\hline Desenvolvimento de Atividades desafiadoras & $15,28 \%$ & $\begin{array}{l}\text { Necessidades de estima } \\
\text { (reconhecimento, status) }\end{array}$ \\
\hline Ambiente de trabalho dinâmico & $9,72 \%$ & $\begin{array}{l}\text { Necessidade social } \\
\text { (relacionamento) }\end{array}$ \\
\hline Ambiente de trabalho calmo & $4,17 \%$ & Necessidade de segurança \\
\hline $\begin{array}{l}\text { As pessoas do novo emprego podem } \\
\text { colaborar para o meu crescimento } \\
\text { profissional }\end{array}$ & $5,56 \%$ & $\begin{array}{l}\text { Necessidade de auto- } \\
\text { realização }\end{array}$ \\
\hline Outras respostas (digitadas pelo pesquisado) & $9,72 \%$ & $\begin{array}{l}\text { Necessidade de auto- } \\
\text { realização }\end{array}$ \\
\hline
\end{tabular}

Outro ponto importante quanto aos aspectos motivacionais se dá em relação aos horários de trabalho. Os horários flexíveis são de grande importância se a empresa deseja reter seus jovens talentos. $77,78 \%$ dos entrevistados consideram a flexibilidade nos horários de trabalho muito importante. Os 22,22\% restantes consideram essa questão de importância relativa e nenhum dos participantes da pesquisa considera sem importância. Outro ponto a destacar, é que $86,11 \%$ dos profissionais consideram essa flexibilização de horários um ponto decisivo para a escolha do emprego.

Fazendo um mapeamento das características de conectividade, para a comunicação dessa geração, destacam-se os seguintes dados: $88,89 \%$ dos entrevistados possuem conta em alguma rede social online e 97,22\% usa sistemas de mensagens instantâneas. Já para a realização de suas tarefas diárias 95,83\% considera a internet como sendo muito importante.

\section{Considerações Finais}

A geração foco da pesquisa descrita por esse trabalho apresenta suas características, pontos fortes e fracos, como todas as outras gerações. De tal forma que suas peculiaridades são apenas diferentes e são fruto do momento histórico e social. Contudo, entender o que levou a construção do pensamento da geração que nasce a partir da década 80 até 1999 é de grande importância para tirar o máximo proveito das características desses profissionais. $\mathrm{O}$ aumento da produtividade baseado nos aspectos motivacionais e a forma de reter esses talentos foram pontos marcantes nesse trabalho.

Segundo a pesquisa realizada, grande parte da mão-de-obra da área de TI é composta por pessoas dessa geração $(83,53 \%)$, demonstrando sua alta relevância nesse 
setor. É importante destacar que o principal objetivo desse trabalho não é quantificar o percentual de pessoas da geração Y no mercado de TI, mas sim mostrar que pessoas dessa geração são os maiores representantes dessa área, e principalmente mapear as características e as motivações dessa geração em relação ao mercado de trabalho.

Esses profissionais buscam, inicialmente, em sua maioria, melhores condições salariais; em um segundo momento são dirigidos por questões de status, conforme a pirâmide de Maslow. Como estratégia para reter esses talentos, reduzindo assim rotatividade nas empresas, é sugerido a criação de plano de carreira que leve em consideração as características dessas pessoas, como por exemplo, a necessidade de crescimento de forma rápida na empresa. Dessa forma, busca-se atender a dois aspectos importantes: a necessidade de melhores salários e a busca de status e reconhecimento. Uma segunda estratégia refere-se a disponibilizar horários flexíveis, pois esses profissionais dão muita importância a essa característica na hora de escolher um emprego.

Esse trabalho apresenta interpretações, possibilidades e hipóteses sobre as características marcantes dessa geração de profissionais. Contudo, ainda existem muitas questões em aberto o que torna esse trabalho importante para a área de recursos humanos nas empresas de computação. Sobretudo, busca servir de embasamento aos líderes de empresas e equipes de desenvolvimento de software.

Como possíveis trabalhos futuros sugere-se:

1.Aplicar a pesquisa quantitativa a outras regiões do Brasil a fim de ter uma maior precisão quanto ao cenário da geração Y no desenvolvimento de software do país;

2.Avaliar, por parte das empresas de desenvolvimento de software, o impacto de conflitos de gerações no ambiente organizacional. Além disso, desenvolver estratégias que possam minimizar as diferenças culturais entre as gerações;

3.Avaliar e buscar diferentes técnicas motivacionais a fim de melhorar o desempenho dos desenvolvedores da geração $\mathrm{Y}$.

\section{Referências}

Veja. (2009) "Sites como Orkut e Facebook se firmam como ambientes de sociabilidade", março de 2010, Disponível em: http://veja.abril.com.br/ noticia/variedade/sites-como-orkut-facebook-se-firmam-como-ambientessociabilidade-420360.shtml,11 de fevereiro de 2009, Acesso em 12 de julho de 2010.

Vieira, E. (2003) "Os Bastidores da Internet no Brasil - As histórias de sucesso e fracassos que marcaram a Web brasileira“, Barueri, São Paulo, Editora Manole

Iannini. T. O. (2010) "Pesquisa do Perfil dos Profissionais de Tecnologia da Informação", março de 2010, Disponível em: www.seprorj.org.br/media/ pesquisa perfil sintese.pdf, Acesso em 10 de julho de 2010.

IBGE. (2009) "O Setor de Tecnologia da Informação e Comunicação no Brasil 20032006", Rio de Janeiro, Brasil, ISBN 978-85-240-4071-9, Disponível em: http://www.ibge.gov.br/home/estatistica/economia/stic/ publicacao.pdf, Acesso em 11 de julho de 2010 . 
Maximiano, A. C. A. (2007) "TEORIA GERAL DA ADMINISTRAÇÃO: Da Revolução Urbana à Revolução Digital”. São Paulo, Brasil, Editora Atlas.

Oliveira, S.(2010) “Geração Y: O Nascimento de uma nova versão de líderes”, São Paulo, Brasil, Editora Integrare, $2^{\mathrm{a}}$ edição.

Weisinger, H. (1997) “INTELIGÊNCIA EMOCIONAL NO TRABALHO”. Rio de Janeiro, Brasil, Editora Objetiva.

Tachizawa, T.; Ferreira, V. C. P.; Mello, A. A. (2006)“GESTÃO COM PESSOAS: Uma abordagem aplicada às estratégias de negócios”. Fortuna. $5^{\circ}$ edição. Editora FGV.

Chiavenato, I. (2000) "INTRODUÇÃO À TEORIA GERAL DA ADMINISTRAÇÃO". 6. ed., São Paulo: Editora Campus. 